\title{
Estágio de Docência e Projetos de Extensão em uma Licenciatura em Língua Estrangeira em EaD no Espírito Santo
}

\author{
Mariza Silva de Moraes*1
} ${ }^{1}$ Professora do Departamento de Línguas e Letras da UFES. Av. Fernando Ferrari, 514, Goiabeiras - Vitória
- ES - Brasil. mariza.sm@ig.com.br

\section{Resumo}

O presente artigo intenciona apresentar o relato de pesquisa pós-doutoral sobre as aporias encontradas na implementação do curso de graduação a distância em italiano no Espírito Santo, pelo Sistema UAB (Universidade Aberta do Brasil). A licenciatura se destina a titular professores leigos. No ente federado não há obrigatoriedade do ensino do idioma, apesar do consistente número de descendentes de italianos no estado. A implementação do projeto apresenta particularidades operacionais: 1) a proposta de curso foi aceita por municípios onde não há campos de estágio; 2) o departamento proponente do curso conta apenas com dois docentes da área; 3) teme-se pela provável falta de candidatos ao cargo de tutor presencial ou a distância que dominem o idioma fora da capital. Desses itens, decorrem as prováveis carências de tutores e de professores para lecionar, supervisionar os estágios, orientar os encontros presenciais e os trabalhos de conclusão de curso. As metodologias usadas foram a bibliográfica e a investigativa. Esta última, na forma de visitas virtuais e físicas ao IFCE, à UFC e à Ufes. O artigo aqui apresentado não traz resultados concretos, mas projeções do que pode ser feito para sanar as aporias quando o curso for instalado. As soluções viabilizadas são: constituir campos de estágio a partir de projetos de extensão (do idioma italiano) para as comunidades firmar convênios institucionais e contar com o recurso do estágio, que resolve as carências de professores e tutores.

Palavras-chave: EaD; estágio de docência; licenciatura em italiano. 


\title{
Teaching Internship and Extension Projects in a Foreign \\ Language Distance Education Licentiate Course in Espirito \\ Santo
}

\begin{abstract}
This article intends to socialize the report of post-doctoral research on the issues encountered in the implementation of licentiate degree in Italian at a distance, in Espirito Santo by the UAB System (Open University of Brazil). The licentiate degree is designed to prepare teachers. In the federated entity there is no mandatory teaching of the language, despite the consistent number of descendants. The implementation presents operational circumstances: 1 ) the proposed course was accepted by municipalities where there is no field for training or internships; 2) the department interested in the course has only two teachers in the area; 3 ) the probable lack of candidates for the post of classroom or distance tutor, who are fluent in the language outside the capital, is feared. From these items derives the probable lack of tutors and teachers to teach, supervise internships, carry out classroom meetings and final papers. The methodologies used were bibliographic and investigative; the latter in the form of virtual and physical visits to IFCE, UFC and Ufes. The article does not bring tangible results, but projections of what can be done to remedy the issues when the course is established. The possible solutions are to form fields from internship and extension projects (of Italian language) to the communities; establish institutional agreements and rely on the use of the Teaching Internship that addresses the needs of both teachers and tutors.
\end{abstract}

Keywords: distance education licentiate course; teacher training; college degree in Italian. 


\section{Introdução}

O Espírito Santo foi colonizado por alguns povos europeus (pomeranos, alemães, italianos, entre outros) distribuídos em diversas localidades. Os municípios de origem europeia preservam as culturas dos antepassados colonizadores por meio da manutenção e transmissão da tradição cultural de cada etnia: gastronomia, folclore, datas comemorativas, religião e idioma.

Temos alguns dados geo-históricos da situação sociolinguística das áreas italianófanas (Moraes, 2014, p. 33). A Universidade do Espírito Santo tem somado esforços para pesquisar, resgatar e, impulsionar a língua dos descendentes de italianos. Para tanto, o Departamento de Línguas e Letras instituiu um grupo de pesquisadores que investiga como "a língua italiana é falada e transformada entre os filhos, netos e bisnetos dos imigrantes". O grupo é capitaneado pela professora Edenize Ponzo, que coordena a pesquisa denominada Italiano no ES. A docente-pesquisadora tem feito suas investigações linguísticas nos municípios de Alfredo Chaves, Cachoeiro de Itapemirim (Burarama), Castelo, Itarana, Jaguaré, Marechal Floriano, Marilândia, Santa Teresa, Vargem Alta e Venda Nova do Imigrante, que têm uma comunidade composta majoritariamente por ítalo-capixabas. Trata-se de um caso de bilinguismo. Os resultados preliminares da pesquisa apontam para a perda progressiva da proficiência oral e escrita do idioma italiano por parte dos cidadãos.

Em termos de preservação da língua-matriz, os italodescendentes se ressentem da atuação do governo em termos educacionais oficiais, visto que a língua italiana não é ofertada regularmente nas escolas da rede pública de ensino (com exceção de Santa Teresa, onde o ensino do idioma é compulsório). Alguns municípios até ofertam a língua italiana de modo experimental, em contra turnos ou como opção de língua estrangeira, ao lado/no lugar dos idiomas espanhol e inglês, mas tanto nestes quanto em Santa Teresa, os professores que lecionam o idioma em tela não têm nenhuma titulação ou apresentam diploma em outra área. Desse modo, os docentes estão inseridos na categoria professor leigo, denominação dada pelo Educacenso (BRASIL, 2008) para os professores em desvio ou carência de titulação acadêmica.

Apesar do consistente número de italodescendentes (as pesquisas censitárias demarcam mais de $70 \%$ do montante populacional), paradoxalmente, não existia nenhuma instituição pública ou privada que ofertasse uma graduação na área de Letras com habilitação em italiano. Atualmente, a Ufes (Universidade Federal do Espírito Santo) 
reconfigurou esse cenário ao ofertar um curso presencial em seu campus de Vitória, que tem previsão de formação da primeira turma para 2017. Vale informar que a oferta do curso de italiano em EaD é uma experiência pioneira no departamento de Letras.

No entanto, a localização do campus da capital não abrange a maioria dos municípios de origem italiana, situados ao longo do território espírito-santense. Nem mesmo os outros dois campi universitários (São Mateus e Alegre) replicam a oferta da graduação em italiano.

É fato que o processo de levar as universidades para o interior é oneroso e demanda muito tempo, além de não alcançar todos os municípios. Nessa perspectiva, o crescimento das instituições de ensino superior (IESs) está sendo viabilizado por meio da educação a distância (EaD), que tem recebido a chancela do MEC (Ministério da Educação) e da Unesco (Organização das Nações Unidas para a Educação, a Ciência e a Cultura) (Sartori, \& Roesler, 2005).

A Ufes está inserida nessa conjuntura porque vem otimizando o acesso dos cidadãos inseridos no quadro topográfico acima descrito aos seus cursos universitários, devido ao trabalho profícuo do Ne@ad (Núcleo de Educação Aberta e a Distância), em parceria com a UAB/MEC (Universidade Aberta do Brasil) e prefeituras, que gerenciam os polos de encontros presenciais.

A sólida experiência do Ne@ad proporciona perspectivas de concretizar a proposta do curso de italiano a distância. Por isso, no ano de 2009, a instituição aderiu à chamada UAB/Capes, por meio do edital Parfor (Plano Nacional de Formação de Professor da Educação Básica), e o curso tinha previsão de implantação em 2015/2.

A graduação em italiano por EaD constitui-se em uma experiência pioneira no âmbito do Departamento de Línguas e Letras, que é consagrado no ensino presencial de português e inglês, tendo, nos últimos três anos, iniciado a oferta de espanhol, francês e italiano como licenciaturas duplas.

\section{Aporias na Implementação do Curso a Distância}


Os cursos a distância têm ancoragem em vários ritos regulatórios, dentre eles a LDB (Leis de Diretrizes e Bases). Destacam-se, neste artigo, as premissas do Decreto n. ${ }^{0}$ 5.622/2005 (Brasil, 2005), que prevê:

Art.10 Para os fins deste Decreto, caracteriza-se a educação a distância como modalidade educacional na qual a mediação didático-pedagógica nos processos de ensino e aprendizagem ocorre com a utilização de meios e tecnologias de informação e comunicação, com estudantes e professores desenvolvendo atividades educativas em lugares ou tempos diversos.

$\S 10$ A educação a distância organiza-se segundo metodologia, gestão e avaliação peculiares, para as quais deverá estar prevista a obrigatoriedade de momentos presenciais para:

I - avaliações de estudantes;

II - estágios obrigatórios, quando previstos na legislação pertinente;

III - defesa de trabalhos de conclusão de curso, quando previstos na legislação pertinente; e

IV - atividades relacionadas a laboratórios de ensino, quando for o caso.

A implementação da licenciatura em EaD defronta-se com diversas aporias, tais como a (provável) carência de professores e tutores para lecionar, orientar monografias e supervisionar estágios, visto que o departamento proponente do curso dispõe de apenas dois professores do setor de italianística e está em curso a primeira turma de graduação em italiano.

No âmbito dos tutores, prevê-se a carência de pessoas que estejam aptas a exercer a tutoria presencial (nos municípios que aderiram ao curso) e que tenham domínio da língua italiana. Agrava a problemática o fato de não existirem campos de estágio na maioria desses municípios, visto que, conforme foi dito, não há obrigatoriedade curricular do ensino da língua em tela.

No intuito de sanar os óbices, realizou-se pesquisa bibliográfica e investigativa (in loco e virtualmente) junto a instituições que ministram cursos em EaD e/ou pesquisam a temática, a saber: Ufes, UFC (Universidade Federal do Ceará) e IFCE (Instituto Federal do Ceará). Além disso, foram também estudadas as diretrizes e protocolos do MEC, da UAB, da Capes (Coordenação de Aperfeiçoamento de Pessoal de Nível Superior) e do CNPq (Conselho Nacional de Pesquisa), que oportunizaram soluções factíveis sob o ponto de vista operacional e legal: 1) Para problema de falta de campos de estágio, serão propostos projetos de extensão do ensino da língua para comunidade pertencente ao 
polo da prefeitura, que dá suporte ao curso; 2) Para a carência de corpo docente e tutorial, ventila-se a contratação de professores e/ou tutores por meio do recurso Estágio de Docência (Brasil, 2006).

\section{Estágio Supervisionado Curricular Obrigatório: Concepção e Estatuto Legal}

Cunha (2010, p. 496) define o estágio como "[...] prática social [, que] é condição de problematização do conhecimento que os estudantes precisam produzir. Nessa perspectiva, a prática não significa a aplicação e confirmação da teoria, mas é a sua fonte".

Carlos (apud Cunha, 2010, p. 109), por sua vez, conceitua o estágio:

[...] os estágios fazem parte de um processo de construção não apenas da docência, mas da própria profissão [...] o estágio aproxima-se, neste sentido, da criação de alternativa de enfrentamento de desafios que surgem da sala de aula, vista como referência e não como prescrição.

Sobre os estágios em curso por EaD, os Referenciais - documento publicado pelo MEC, em 2007, que estabelece as diretrizes para o funcionamento de cursos a distância - recomendam observar o que está disposto sobre o assunto nos projetos pedagógicos dos cursos.

No que diz respeito à obrigatoriedade do estágio, o projeto pedagógico do curso de Letras - Italiano (licenciatura simples) foi elaborado a partir das diretrizes propostas pela Resolução CNE/CP (Conselho Nacional de Educação) n. 0 1, de 18 de fevereiro de 2002 - baseada no Parecer CNE/CP n.o 009/2001, que estabelece as Diretrizes Curriculares Nacionais para a Formação de Professores da Educação Básica - e pela Resolução CNE/CP n. ${ }^{\circ}$ 2, de 19 de fevereiro de 2002 - com base nos Pareceres CNE/CP n. ${ }^{\circ}$ s 27 e 28/2001, que põem em discussão as 400 horas de Estágio Supervisionado Curricular obrigatório.

Posteriormente, a Lei 11.778/2008 (Lei do Estágio/Ministério do Trabalho) resgata o disposto no conjunto de normas acima citado e se torna um referencial para coordenadores, professores, empregadores e alunos a respeito do estágio para graduandos, como atestam os primeiros artigos da lei em discussão: 
Art. 10 Estágio é ato educativo escolar supervisionado, desenvolvido no ambiente de trabalho, que visa à preparação para o trabalho produtivo de educandos que estejam frequentando o ensino regular em instituições de educação superior, de educação profissional, de ensino médio, da educação especial e dos anos finais do ensino fundamental, na modalidade profissional da educação de jovens e adultos.

Art. $2^{\circ}[\ldots] \S 1{ }^{\circ}$. Estágio obrigatório é aquele definido como tal no projeto do curso, cuja carga horária é requisito para aprovação e obtenção de diploma. (Brasil, 2014).

A Universidade Federal do Espírito Santo apresenta uma série de exigências em relação ao estágio curricular, regularizado por meio de instrumentos normativos (Ufes Daocs, Resoluções 74/2010 e 75/2010).

\section{Campos de Estágio}

Os documentos legais, provenientes do MEC, abalizam a concepção e escolha dos projetos de estágios curriculares. O CNE/CP 09/2001, item 3.1, determina ser necessário:

[...] instituir tempos e espaços curriculares diversificados como oficinas, seminários, grupos de trabalho supervisionado, grupos de estudo, $[\ldots]$, atividades de extensão [...] capazes de promover e, ao mesmo tempo, exigir dos futuros professores atuações diferenciadas, percursos de aprendizagens variados, diferentes modos de organização do trabalho, possibilitando o exercício das diferentes competências a serem desenvolvidas. (Brasil, 2001).

Sobre os campos de estágio, os Referenciais (Brasil, 2007) recomendam que se identifiquem, no projeto pedagógico de cada instituição, os espaços para estágios supervisionados determinados pela legislação, oferecendo a estrutura adequada aos professores responsáveis por esse exercício, o que garantiria momentos privilegiados de articulação teórico-prática.

De acordo com dados acima expostos, pretende-se alocar os estagiários em campos de tirocínio onde o italiano seja ensinado, ou seja, fora daqueles municípios que não incluem tal idioma em suas escolas. O estágio será feito na forma de projeto de extensão (a partir do estipulado pela pró-reitoria de extensão da Ufes) e se configura como estratégia de aprendizagem que privilegia a percepção do contexto sócio-histórico 
da escola e da comunidade. Será oferecido em associações de moradores, ONGs, espaços disponíveis das prefeituras ou de setores privados que aceitem a proposta de extensão e que apresentem infraestrutura para abrigar o alunado.

Dependendo das condições materiais e das instalações físicas locais, o projeto de extensão de ensino da língua italiana poderá se valer do próprio instrumental digital no qual o curso está suportado, ou seja, o Ambiente Virtual de Aprendizagem (AVA), que será programado e customizado para a empreitada didática. O curso de extensão, em sua versão digital, pode contar também com recursos gratuitos de aprendizagem que o portal do MEC oferece para a coleta de material instrucional, como o Domínio Público, o Banco Internacional de Objetos de Aprendizagem, o DVD Escola e o Mídias na Educação.

\section{Docência Superior}

Nos circuitos universitários, há uma preocupação sobre a formação dos professores para atuarem no ensino superior, devida ao fato de que os critérios de titulação e erudição não estão mais atendendo às demandas do ensino-aprendizagem nesse nível de docência. Aparentemente, a formação pedagógica/andragógica do professor, quando emanada das licenciaturas, não é satisfatória.

Algumas instituições privadas ofertam, em seu cardápio de graduações, um curso que se ocupa da formação para o ensino superior. Alguns teóricos da educação iniciaram estudos sobre o tema, dentre os quais destaca-se Maria Isabel da Cunha, professora pesquisadora do CNPq que se dedica à Pedagogia Universitária. Trata-se de um campo interdisciplinar de estudos que visa dar nova fundamentação teórico-epistemológica ao docente do ensino superior. A autora possui uma série de livros sobre o assunto.

Nesse meio, há alunos provenientes das licenciaturas que continuam os estudos, frequentando cursos de pós-graduação, sem apresentar passagem pelo magistério no ensino fundamental ou médio. Outros, por sua vez, estão na pós-graduação de cursos que têm como mercado de trabalho o ensino superior, mas não são sequer provenientes de licenciaturas. Ambas as categorias, ao ingressarem no ensino universitário, podem encontrar dificuldades no exercício da docência.

Em suma: a docência superior precisava institucionalizar o protagonismo dos programas de pós-graduação e vem fazendo isso por meio do Estágio de Docência. 


\section{Estágio de Docência}

O Programa Estágio de Docência foi oficializado pela Capes como componente curricular obrigatório aos alunos bolsistas dos cursos stricto sensu. As normas para o programa foram fixadas pelo regulamento do Programa de Demanda Social (DS), que apresenta os Objetivos do Programa e Critérios para Concessão de Bolsas de Estudos por meio da Portaria n. ${ }^{0}$ 129/2006 - Capes (13 de dezembro de 2006).

A portaria prevê: a) compatibilidade do estágio com a grande área e com subáreas do programa de pós-graduação; b) obrigatoriedade para os bolsistas do Programa de Demanda Social (mestrado e doutorado); c) duração mínima de um semestre para o mestrado e dois para o doutorado; d) carga horária máxima semanal de quatro horas; e) compete à Comissão de Bolsas Capes/DS registrar e avaliar o Estágio de Docência para fins de crédito do pós-graduando, bem como a definição quanto à supervisão e o acompanhamento do estágio; f) o pós-graduando deve elaborar um relatório das atividades realizadas e apresentar ao orientador, que avaliará o resultado, e o conceito será inserido no histórico escolar do aluno.

As informações relativas à disciplina ministrada sob a supervisão do orientador podem ser expostas no histórico escolar do bolsista. Por se tratar de atividade curricular, a participação de alunos do programa no Estágio de Docência não cria vínculo empregatício, nem será remunerada.

A recepção do Estágio de Docência por parte dos coordenadores dos programas de pós-graduação não foi bem acolhida porque, para eles, a exigência da Capes poderia prejudicar a dedicação exclusiva aos estudos (condição basilar da concessão de bolsas de pesquisa) e poderia haver negligências para com os prazos estipulados (para integralização do mestrado e do doutorado) pela própria agência de fomento; por fim, eles defenderam que isso constituiria "alternativa barata para eventuais dificuldades de contratação de professores" (Cunha, 2010, p. 109). Apesar das dúvidas e críticas iniciais, os pós-graduandos apoiam o programa, que tem sido útil e transferido aportes à formação docente. 


\section{Participação de Pós-graduandos no Programa de Estágio de Docência na}

\section{EaD}

O departamento do qual emana o curso de italiano conta com dois programas no âmbito de Literatura e Linguística. A prática do Estágio de Docência está sendo realizada há alguns anos nos cursos de Letras, com resultados satisfatórios.

É sabido que as agências federais de fomento aos programas de pós-graduação não permitem o acúmulo de bolsas de estudos por parte dos alunos beneficiados pelo Programa de Demanda Social. Notadamente, os bolsistas da UAB no exercício da tutoria ou da função de professor de conteúdo ou professor formador em programas de EaD também não podem acumular bolsas de estudos.

[...] o governo fez a previsão de como seria feita a remuneração e qual o perfil dos profissionais vinculados ao sistema UAB. Definiu-se, então, que a remuneração seria feita por meio da concessão de bolsas de estudo e de pesquisa, autorizadas pela Lei no 11.273/2006, que sofreu algumas modificações pela Lei no 11.502/2007. Com base na "lei de bolsas", a Capes dispôs sobre os participantes e as bolsas que cada um deles faria jus, definindo que "fazem jus ao recebimento de uma única bolsa por período, mesmo que exerçam mais de uma função no âmbito do Sistema $U A B$ ", sendo "vedada a acumulação de mais de uma bolsa de estudo ou pesquisa nos programas de que trata esta Lei"(Lei no 11.273/2006, Art. $1^{\circ}, \S 3^{\circ}$ ). (Oliveira, 2013, p. 56).

O CNPq (Conselho Nacional de Pesquisa) e a Capes abrem exceção para profissionais que atuam na tutoria no sistema UAB:

A única exceção a essa regra é o caso disposto pela portaria conjunta Capes CNPq de 12 de dezembro de 2007, que diz: "Os bolsistas da Capes e do CNPq, matriculados em programas de pós-graduação no país, selecionados para atuar nas instituições públicas de ensino superior como TUTORES do sistema UAB, terão as respectivas bolsas de estudo preservadas pelas duas agências, pelo prazo da sua duração regular. (Lei n० 11.273, de 6 de fevereiro de 2006 e a Lei no 11.502, de 11 de julho de 2007)." (Brasil, 2014).

Assim, tutores podem receber pagamento pela UAB e manter a bolsa de estudos pelas agências federais.

Com base na Portaria Conjunta Capes/CNPq n. ${ }^{\circ}$ 01, de 12/12/2007, estudantes regularmente matriculados em cursos de pós-graduação stricto sensu que recebem bolsa da Capes e do CNPq podem acumular esta bolsa com a de tutor. A última atualização no 
valor das bolsas da UAB foi feita pela Resolução/CD/FNDE n.o 8, de 30/04/2010. Quanto aos participantes/bolsistas que atuam na EaD da Capes/UAB, essa resolução dispõe que o Fundo Nacional de Desenvolvimento da Educação (FNDE) pagará bolsas aos seguintes beneficiários: coordenador/coordenador-adjunto da UAB, coordenador de curso, coordenador de tutoria, professor-pesquisador conteudista, professor-pesquisador, coordenador de polo e tutor. Este último participante é regularmente nominado nas IES como tutor presencial e tutor a distância (OLIVEIRA, 2013, p. 56). No entanto, a tutoria não tem, neste formato, nenhum compromisso didático com o curso stricto sensu ao qual pertença o tutor.

\section{Conclusão}

As soluções para sanar os obstáculos da operacionalização do curso em EaD na área de Italiano no Espírito Santo foram: resolver, de forma pragmática, a ausência de campos de estágio e a carência de professores e tutores, por meio da legislação vigente, que ordena os estágios supervisionados na graduação e o Estágio de Docência na pósgraduação.

Compreende-se que a adesão a um edital de tutores do sistema UAB é um ato volitivo. Não significa que o interessado terá a supervisão de um professor, compilará um relatório final e receberá créditos em sua integralização curricular, como descrito na Portaria da Capes para o Programa de Estágio de Docência.

Concebe-se que a participação de estudantes dos programas de pós-graduação da Ufes no curso de Italiano gere possibilidades de articulações na formação de professores do ensino superior e integre a pós-graduação à graduação a distância.

A participação de mestrandos e doutorandos na licenciatura divulgará a EaD e o curso em discussão. Há a perspectiva de que, por consequência, amplie-se o mercado de trabalho do pós-graduando, dando ensejo à profissionalização da tutoria e à criação de cursos para a formação (e formação continuada) dessa categoria. A experiência, se for positiva, gerará, para o departamento cedente, motivos para reduplicar a iniciativa.

Quanto ao campo de estágio, vislumbra-se que projetos de extensão abrem a instituição para a comunidade, inserindo-se no lócus onde os polos estão instalados. Assim, retiram da invisibilidade a instituição (sem campus universitário) que oferta o 
curso. Por se tratar de uma licenciatura, o projeto extensório publiciza o curso e fortalece o desejo de abertura de concursos públicos para provimento de vagas de professor na área, com vista a planos de carreira. Se bem-sucedido, o curso fornece dados positivos para o Educacenso sobre a extinção da categoria de professor leigo no âmbito da língua italiana no Espírito Santo.

\section{Referências Bibliográficas}

Brasil. (2005). Decreto n.o 5.622, de 19 de dezembro de 2005. Disponível em http://www.planalto.gov.br/ccivil 03/ ato2004-2006/2005/decreto/d5622.htm

Brasil. (2008).

Educacenso. Disponível em

http://www.educacenso.inep.gov.br/censobasico/\#/

Brasil. (2008). Lei n.o 11.788, de 25 de setembro de 2008. Disponível em http://www.planalto.gov.br/ccivil 03/ ato2007-2010/2008/lei/l11788.htm

Brasil. (2001). Parecer CNE/CP, de 8 de maio de 2001. Diário Oficial da União, Brasília, DF, 18 jan. 2002, Seção 1, p. 31.

Brasil. (2001). Parecer CNE/CP, de 2 de outubro de 2001. Diário Oficial da União, Brasília, DF, 18 jan. 2002, Seção 1, p. 31.Brasil. (2010). Portaria MEC/Capes n.o 76, de 14 de abril de 2010. Disponível em http://www.meau.ufba.br/site/arquivos/portaria-capes-762010-concessao-de$\underline{\text { bolsas }}$

Brasil. (2006). Portaria MEC/Capes n. 129, de 13 de dezembro de 2006. Disponível em

https://www.capes.gov.br/images/stories/download/relatorios/Portaria PROSUP. pdf

Brasil. (2007). Referenciais de qualidade para ensino superior a distância. Disponível em http://portal.mec.gov.br/seed/arquivos/pdf/legislacao/refead1.pdf

Brasil. (2014). Bolsas. Universidade Aberta do Brasil. Disponível em http://uab.capes.gov.br/index.php/cursos-274841/43-bolsas-93819144 
Cunha, M. I. da. (2010). Trajetórias e lugares de formação da docência universitária: da perspectiva individual ao espaço institucional. Araraquara: Junqueira e Marin/ Brasília: Capes/CNPq.

Fagundes, L., Maçada, D., \& Sato, L. (1999). Aprendizes do futuro: as inovações começaram!. Brasília: USP/ Estação Palavra.

Moraes, M. (2014). Política linguística em prol da licenciatura em italiano na modalidade EaD no Espírito Santo. Web Revista Sociodialeto, 5(13), 318-331.

Oliveira, E. N. (2013). Docência na Educação a Distância da UFGD, EaD \& Tecnologias Digitais na Educação, 1(2), 8-21.

Pimenta, S. G. (2000). A pesquisa em Didática (1996-1999). In Didática, currículo e saberes escolares. Rio de Janeiro: DP\&A.

Pimenta, S. G. (2002). Professor reflexivo: construindo uma crítica. In S. G., Pimenta \& E. Ghedin (Orgs.). Professor reflexivo no Brasil: gênese e crítica de um conceito. São Paulo: Cortez.

Pimenta, S. G. (2002). De professores, pesquisa e didática. Campinas: Papirus.

Pimenta, S. G. (1994). O estágio na formação de professores: unidade teoria e prática?. São Paulo: Cortez.

Pimenta, S. G. (1999). Saberes pedagógicos e atividade docente. In S. G. Pimenta (Org.). Saberes da docência. São Paulo: Cortez, 1999.

Sartori, A., \& Roesler, J. (2005). Educação superior a distância: gestão da aprendizagem e da produção de materiais didáticos impressos e online. Tubarão: Editora Unisul.

Universidade Federal do Espírito Santo. (2010). Resolução n.o 74 - CEPE. Disponível em http://www.daocs.ufes.br/resolu\%C3\%A7\%C3\%A30-n\%C2\%BA-742010cepe

Universidade Federal do Espírito Santo. (2010). Resolução n.o 75 - CEPE. Disponível em http://www.daocs.ufes.br/resolu\%C3\%A7\%C3\%A30-n\%C2\%BA-752010cepe 
Universidade Federal do Espírito Santo. (2013). Pós-Graduação. Disponível em http://www.literatura.ufes.br/pos-graduacao/PPGL\&task=view

Universidade Federal do Espírito Santo. (2013). Pró-reitoria de Pesquisa e Pósgraduação. Disponível em www.prppg.ufes.br 